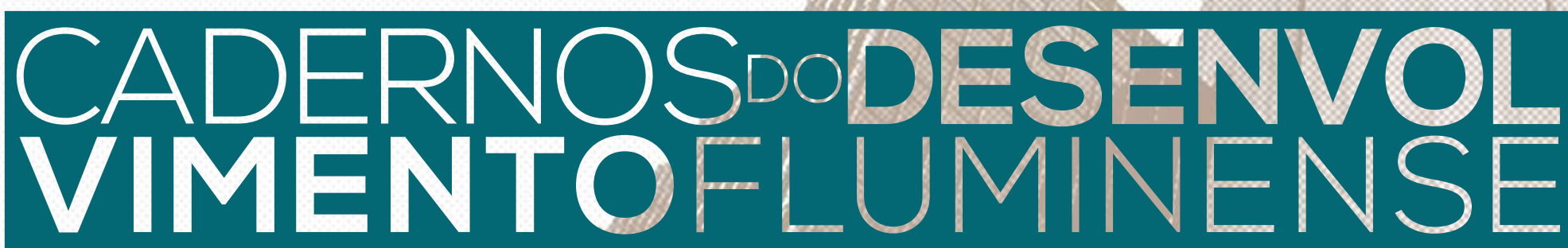

16

ANO $2019 \mid 1^{\circ}$ semestre

- Especialização produtiva - reflexos sobre o

desenvolvimento do estado do Rio de Janeiro;

- Relação entre renda petrolífera e melhoria na

qualidade de vida por municípios

confrontantes da Bacia de Campos;

- Desafios à gestão, ao desenvolvimento sustentável em Miracema;

- Inovação e Desenvolvimento Regional - uma análise sobre a produção científica da Universidade Estadual do Norte Fluminense e sua potencial contribuição para a sociedade;

- Perfil socioeconômico de feirantes do mercado municipal de Campos dos Goytacazes;

- Casa popular própria - ilusão ou solução;

- Capilaridade territorial na provisão de medicamentos básicos no estado do Rio de Janeiro;

- NudgeRio um caso de aplicação de Ciência Comportamental às Políticas Públicas;

- Mulher, política e cidade - reflexões analíticas.
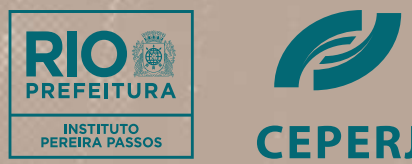


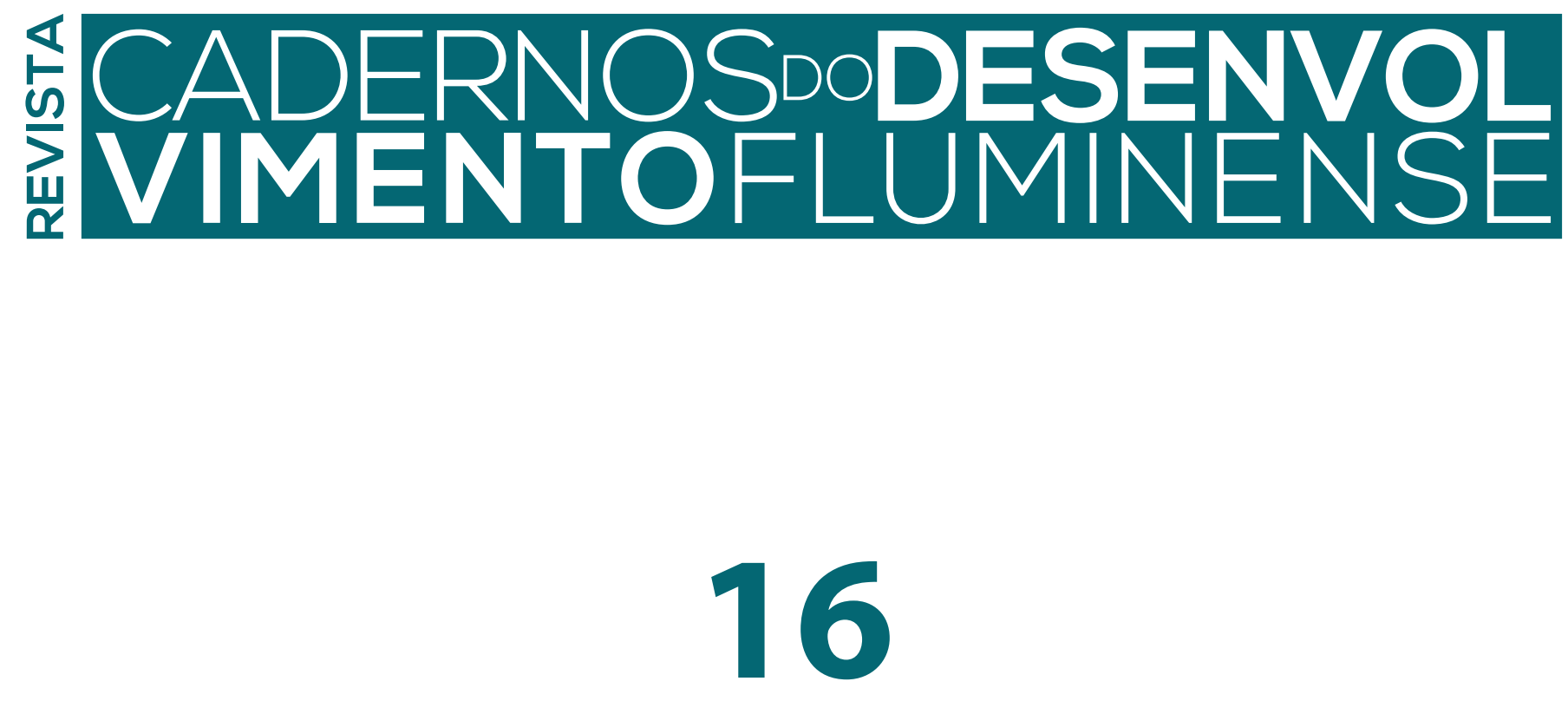

ANO 2019 $\mid 1^{\circ}$ semestre 
FUNDAÇÃO CENTRO ESTADUAL DE ESTATÍSTICAS, PESQUISAS E FORMAÇÃO

DE SERVIDORES PÚBLICOS DO RIO DE JANEIRO — CEPERJ

PRESIDÊNCIA

Pedro Castilho

ESCOLA DE GESTÃO E POLÍTICAS PÚBLICAS

Homero de Araújo Torres

CENTRO DE ESTATÍSTICAS, ESTUDOS E PESQUISAS

Fabio Odilon Alves Gomes

DIRETORIA DE CONCURSOS E PROCESSOS SELETIVOS

Lisandro Junior

DIRETORIA DE COOPERAÇÃO TÉCNICA E DES. INSTITUCIONAL

Tatiani Lisboa

DIRETORIA ADMINISTRATIVA E FINANCEIRA

Marcelo Serrano Peixoto

INSTITUTO PEREIRA PASSOS — IPP

DIRETOR-PRESIDENTE

Mauro Osorio

COORDENADOR TÉCNICO DE INFORMAÇÕES DA CIDADE

Carlos Krykhtyne

COORDENADORA TÉCNICA DE PROJETOS ESPECIAIS

Andrea Pulici

COORDENADOR DE COMUNICAÇÃO

Bruno Filippo 


\section{Editores}

EDITORES CIENTÍFICOS

Jorge Britto • UFF

Lia Hasenclever • Instituto de Economia - UFRJ

EDITOR EXECUTIVO

Bruno Filippo • IPP

\section{CONSELHO EDITORIAL}

Bruno Leonardo Barth Sobral • Faculdade de Ciências Econômicas - UERJ

Carlos Antonio Brandão • Inst. de Pesquisa e Planejamento Urbano e Regional - UFRJ

Fabiano Guilherme Mendes Santos • Instituto de Estudos Sociais e Políticos - UERJ

Glaucio José Marafon • Instituto de Geografia - UERJ

Jorge Nogueira de Paiva Britto • Faculdade de Economia - UFRJ

José Luis Vianna da Cruz • Centro de Pesquisa Candido Mendes - UCM

Lia Hasenclever • Inst. de Economia - UFRJ / Universidade Cândido Mendes

Campos - UCAM Campos

Luis Fernando Valverde Salandía • Instituto Pereira Passos

Luiz Martins de Melo • Instituto de Economia - UFRJ

Maria Alice Rezende de Carvalho • Depto. de Ciências Sociais - PUC RJ

Maria Lucia Teixeira Werneck Vianna • Instituto de Economia - UFRJ

Maria Helena de Macedo Versiani • Instituto Brasileiro de Museus

Marieta de Moraes Ferreira • Fundação Getúlio Vargas

Mauro Osorio • Faculdade Nacional de Direito - UFRJ

wMiguel Antonio Pinho Bruno - Escola Nacional de Ciências Estatísticas - IBGE /Fac. de Ciên-

cias Econômicas - UERJ / Mackenzie Rio

Nelson de Castro Senra • Escola Nacional de Ciências Estatísticas - IBGE

Paulo Alcântara • Universidade Cândido Mendes - UCAM

Paulo Knauss Mendonça • Depto. de História - UFF

Pedro Abramo • Instituto de Pesquisa e Planejamento Urbano Regional - UFRJ

Renata Lèbre La Rovere • Instituto de Economia - UFRJ

Roberto de Andrade Medronho • Instituto de Estudos em Saúde Coletiva - UFRJ

Rosélia Périssé Piquet • Centro de Pesquisa Candido Mendes - UCM

Sergio Ferraz Magalhães • Faculdade de Arquitetura e Urbanismo - UFRJ

Silvia Ramos • Centro de Estudos de Segurança e Cidadania - UCM

\section{REVISTA CADERNOS DO DESENVOLVIMENTO FLUMINENSE}

\section{COORDENAÇÃO}

Bruno Filippo

SECRETARIA EXECUTIVA

Ariana Falcão

REVISÃo

De responsabilidade dos autores

PROJETO GRÁFICO E DIAGRAMAÇÃO

Cláudio Novaes

R. São Francisco Xavier, 524/SI. 1050, Bloco FS - Maracanã

Rio de Janeiro • RJ - CEP 20550-013 - Telefone: (21) 2334-7313

revistacadernos.ceperj@gmail.com | www.e-publicacoes.uerj.br/ojs/index.php/cdf 



\section{Editorial}

Os Editores tem a satisfação de apresentar o conteúdo do $16^{\circ}$ número da REVISTA CADERNOS DO DESENVOLVIMENTO FLUMINENSE, que reflete o compromisso com uma reflexão acadêmica multidisciplinar sistemática tanto sobre contexto sócio-econômico-territorial do estado do Rio de Janeiro (ERJ), como também sobre orientações e práticas relevantes no campo das políticas públicas, orientadas para os enfrentamentos de desafios colocados em função de transformações contemporâneas da sociedade fluminense em suas múltiplas dimensões. Seguindo essa tradição, o presente número contempla tanto artigos baseados em reflexões de natureza mais geral, como abordagens mais focalizadas, em termos tanto do objeto de reflexão como do campo associado das políticas públicas. Traz colaborações de várias instituições do ERJ e abordagens de distintos campos disciplinares.

Em primeiro lugar, cabe destacar artigos com foco mais amplo em termos do diagnóstico socioeconômico do Estado do Rio de Janeiro, seja através de abordagens que contemplam tanto a configuração geral da estrutura produtiva, seja através de análises territorialmente mais localizadas da dinâmica socioeconômica. O artigo “Especialização produtiva: reflexos sobre o desenvolvimento do estado do Rio de Janeiro", de Henrique Cavalieri e Lia Hasenclever, analisa a evolução da estrutura produtiva do Estado do Rio de Janeiro, em comparação com a nacional. Ressalta-se a concentração em segmentos associados ao petróleo e mostra-se que essa especialização produtiva não tem se constituído em uma via de desenvolvimento virtuoso para o estado, pois tende a perpetuar e reproduzir heterogeneidades estruturais, refletidas em tendências de baixo crescimento econômico e vulnerabilidade externa.

No campo de um diagnóstico socioeconômico territorialmente mais localizado, o artigo "Relação entre renda petrolífera e melhoria na qualidade de vida por municípios confrontantes da Bacia de Campos", de Roberto Meireles Acruche, Ítalo de Oliveira Matias, Milton Erthal Jr, Fabio Freitas da Silva e Aldo Shimoya, tem como foco os nove municípios fluminenses pertencentes à Bacia de Campos. Por meio de uma pesquisa que usa o método de análise multicritério e dados do Índice FIRJAN (Federação das Indústrias do Rio de Janeiro) de Desenvolvimento Municipal, classifica os municípios e compara esta ordenação ao montante de rendas petrolíferas recebidas. Aponta-se que maiores níveis de royalties per capita não estão associados a melhores condições de desenvolvimento humano e constata-se uma dependência financeira dos municípios em relação à transferência e royalties acima de $70 \%$, com exceção da cidade de Macaé por concentrar a atividade petrolífera na região, sugerindo-se que a abundância de recursos naturais levou tanto a um afrouxamento fiscal e a uma tendência a negligenciar políticas públicas que estimulassem o desenvolvimento local.

Em sequência, o artigo "Desafios à gestão, ao desenvolvimento sustentável em Miracema (RJ)", de Paulo José de Mendonça Ribeiro, discute os impactos da criação de UC - Unidade de Conservação (UC) no município de Miracema, em 2010 como estratégia para promoção de um município "saudável e sustentável". Foi feita uma pesquisa de campo sobre: problemas de saneamento básico (lixo, esgoto, água e drenagem) e ambientais (erosão, desmatamento, contaminação da água), de modo a verificar em que medida a problemática socioambiental incorpora as questões relativas a qualidade de vida e bem-estar dos indivíduos e coletividades. As evidências coletadas sugerem que há mais custos que benefícios, particularmente no que se refere à sustentabilidade socioambiental, que representa um grande desafio para as políticas públicas.

O artigo "Inovação e Desenvolvimento Regional: uma análise sobre a produção científica da Universidade Estadual do Norte Fluminense e sua potencial contribuição para a sociedade", de Raquel Chaffin Cezario, Edson Terra Azevedo Filho e Henrique Rego Monteiro da Hora, pro- 
cura discutir, com base na experiência da Universidade Estadual do Norte Fluminense Darcy Ribeiro - UENF, o papel da universidade na sociedade, por meio da produção de conhecimento e da capacidade de induzir o desenvolvimento regional via inovação. A metodologia contempla uma abordagem quali-quantitativa mediante pesquisa bibliométrica no Banco de Dados Scopus. Constatou-se que a UENF tem gerado conhecimento relevante, por meio de publicações de documentos, principalmente na área das Ciências Agrárias e Biológicas, apresentando um potencial inovador capaz de contribuir com o desenvolvimento da Região desde que haja engajamento entre ela, governo e empresa, numa Hélice Tríplice.

Considerando um foco mais microscópico na abordagem da problemática do desenvolvimento socioeconômico local, o artigo "Perfil socioeconômico de feirantes do mercado municipal de Campos dos Goytacazes" de Graciela Aparecida Profeta, Raquel Chaffin Cezario, Elen Cristina de Mattos Lima e Vanuza da Silva Pereira Ney, procura caracterizar o perfil socioeconômico de feirantes de hortifrutícolas do mercado municipal de Campos dos Goytacazes, considerando aspectos relacionados aos canais de comercialização e as características econômicas que diferenciam os feirantes. Os resultados obtidos apontam que a renda mensal oriunda da feira era de extrema importância na composição da renda total da família, e, portanto, na sobrevivência das mesmas. Constatou-se também que os feirantes não usavam os circuitos curtos de produção que garantiriam a comercialização da produção local e que isso, além de não lhes fornecer produtos diferenciados para a venda, ainda implicava em perda de receita, pois acabavam competindo em condições desiguais com os supermercados da cidade.

$\mathrm{Na}$ transição entre abordagens de cunho mais analítico e abordagens com foco mais direcionado para a avaliação de políticas, o artigo "Casa popular própria: ilusão ou solução?", de Bianca Siqueira Gonçalves, Livia Maria de Souza Almeida Coura e José Luis Vianna da Cruz, é de natureza essencialmente conceitual, procurando discutir aspectos capazes de nortear a implementação de políticas habitacionais e urbanas, conectando a discussão do sonho de consumo da propriedade de um lugar para morar com as possibilidades de efetivação do direito à cidade, através de um revisão não sistemática da bibliografia sobre a origem da casa como mercadoria e objeto de desejo do trabalhador e sobre a questão da segregação sócio espacial à luz do Direito à Cidade. Ao mesmo tempo, procura-se articular essa discussão a aspectos importantes da estrutura e dinâmica da cidade, ressaltando-se o papel do planejamento urbano no sentido de mitigar a segregação socioespacial.

No campo mais operacional da avaliação de políticas, o artigo "Capilaridade territorial na provisão de medicamentos básicos no estado do Rio de Janeiro", de Eduardo Manhães e Lia Hasenclever, analisa a Política Pública de Assistência Farmacêutica (AF) nas mesorregiões do estado do Rio de Janeiro por meio da distribuição territorial das Unidades Básicas de Saúde (UBS) e dos estabelecimentos do Programa Farmácia Popular do Brasil. Aborda ainda a relação existente entre a instalação de unidades de AF com o volume populacional e a renda média per capita das mesorregiões no ano de 2018. A partir da construção de indicadores e da análise da correlação entre as variáveis, constata-se que, apesar de ter havido uma expansão da provisão de medicamentos, os estabelecimentos da rede credenciada são mais concentrados e os das UBS são mais dispersos no território, o que indica um melhor desempenho destas últimas em termos de distribuição territorial.

Ainda no campo da operacionalização de políticas públicas, o artigo "NudgeRio: um caso de aplicação de Ciência Comportamental às Políticas Públicas", de Otávio Morato de Andrade, discute possíveis soluções para políticas públicas baseadas em insights e fundamentos teóricos da Economia Comportamental, mais conhecidos como Nudges, termo que sugere a associação de incentivos comportamentais para reverter falhas cognitivas e que podem inspirar a criação de novas estratégias de aderência às políticas públicas. Especificamente, procura-se discutir com exemplos práticos de aplicações de Nudges no âmbito da governança estatal, em especial, o caso da NudgeRio, unidade criada na Prefeitura da Cidade do Rio. Refere-se ao caso da implementação do Programa Líderes Cariocas (PLC), coordenado pelo Instituto Fundação João Goulart (IFJG), que procura selecionar servidores públicos com perfil de liderança positiva e capacitá-los para assumir posições proeminentes na administração pública municipal. 
Por fim, no campo mais amplo da representação política, mas ainda com claros desdobramentos na definição de políticas públicas, o artigo "Mulher, política e cidade: reflexões analíticas", de Aimée Seixas de Sousa e María Gabriela Scotto, discute as relações entre mulheres, cidade, feminismo e participação em espaços de representação política. O caso da pesquisa em foco é a presença feminina na Câmara Municipal do Rio de Janeiro. Especificamente, a partir da implementação das cotas eleitorais para mulheres, busca-se discutir as relações entre a participação política e o direito à cidade sob a concepção de gênero. Argumenta-se que, numa perspectiva feminista, é possível pensar a mulher presente e atuante na política municipal como planejadora do espaço urbano e da vida das cidades, avaliando de maneira mais clara suas pretensões, interesses e demandas, apontando-se a necessidade de autonomia feminina no que diz respeito aos seus direitos como cidadãs e às escolhas sobre o acesso e a função do espaço público.

O conjunto de artigos presentes nesse número da REVISTA CADERNOS DO DESENVOLVIMENTO FLUMINENSE reflete o caráter multidisciplinar da discussão sobre o desenvolvimento fluminense e o compromisso em relação à avaliação de políticas públicas que norteiam a nossa linha editorial. Além disso, destacamos o compromisso do Conselho Editorial e das instituições de apoio no sentido de dar maior celeridade à avaliação das submissões e à atualização do processo de edição. É com base nessa perspectiva que reiteramos o convite à comunidade acadêmica para novas submissões que enriqueçam ainda mais a Revista. 



\title{
NudgeRio: um caso de aplicação de Ciência Comportamental às Políticas Públicas
} NudgeRio: a case of application of Behavioral Science to Public Policies

Otavio Morato de Andrade ${ }^{1}$

\begin{abstract}
RESUMO
As soluções para políticas públicas baseadas em insights comportamentais, mais conhecidos como Nudges, têm se mostrado simples e de baixo custo, exibindo grande potencial para influenciar positivamente a qualidade de vida da sociedade. Este estudo sintetiza as bases e os fundamentos teóricos da Economia Comportamental, esclarecendo de que forma estes conceitos científicos podem ser aplicados na prática para formular políticas regulatórias. Também foram analisados exemplos práticos de aplicações de Nudges no âmbito da governança estatal, em especial, o caso da NudgeRio, unidade criada na Prefeitura da Cidade do Rio, que tem por objetivo o estudo e a implementação de projetos de ciência comportamental aplicada. Ao final, conclui-se pela viabilidade da concepção de políticas públicas baseadas em Economia Comportamental e em testes randomizados, como forma de se aperfeiçoar a conduta individual e coletiva através da transformação do contexto de escolhas oferecido ao cidadão.
\end{abstract}

PALAVRA-CHAVE: NudgeRio. Nudges. Políticas Públicas. Economia Comportamental. Vieses Cognitivos.

\begin{abstract}
Public policy solutions based on behavioral insights, better known as Nudges, have been shown to be simple and low cost, showing great potential to positively influence society's quality of life. This study synthesizes the bases and theoretical foundations of Behavioral Economics, clarifying how these scientific concepts can be applied in practice to formulate regulatory policies. Practical examples of applications of Nudges in the scope of state governance were also analyzed, in particular, the case of NudgeRio, a unit created in the City of Rio de Janeiro, which aims to study and implement applied behavioral science projects. In the end, it is concluded that the conception of public policies based on Behavioral Economics and randomized tests is feasible, as a way to improve individual and collective conduct through the transformation of the context of choices offered to the citizen.
\end{abstract}

KEYWORDS: NudgeRio. Nudges. Public Policies. Behavioral Economics. Cognitive Biases.

\section{Introdução}

As ciências comportamentais baseiam-se em novos achados da psicologia e da economia para tentar entender e prever o comportamento humano (JACKSON, 1994, p. 144). Os pesquisadores desta área têm ressaltado que, em diversos contextos, as pessoas escolhem mal. E nem sempre aprendem a fazer escolhas corretas, mas persistem sistematicamente no erro (HAMMOND et al, 1998, p. 20).

Até a década de 1960, a maioria das pesquisas econômicas partiam do modelo de agente racional, o homem econômico. Para esta teoria, as decisões de um indivíduo seriam resultado de uma ponderação pragmática entre suas preferências pessoais e os custos/benefícios envolvidos no contexto de escolha (ANDRADE e DIAS, 2001, p. 41). Essas premissas foram questionadas a partir da década de 1970 por psicólogos e economistas, que passaram a fornecer uma nova estrutura para compreender quando e como as pessoas cometem erros (KAHNEMAN \& TVERSKY, 2012, p. 10). 
Apoiados nestas descobertas, os cientistas propuseram a criação de "incentivos comportamentais", que alteram o comportamento das pessoas de forma previsível, guiando e influenciando-as a fazerem melhores escolhas. Demonstrou-se que, no processo de tomada de decisão humana, a racionalidade é limitada por fatores psicológicos, associações emotivas (vieses de intuição) e suposições mentais automatizadas que distorcem a estatística da realidade de modo que os sujeitos nem sempre são aptos a escolher a melhor decisão para si (KAHNEMAN e TVERSKY, 1974, p. 1124-1131).

Assim foi proposto o Nudge: uma ferramenta capaz de orientar o comportamento, otimizando as escolhas do cidadão ao incentivar comportamentos mais seguros e saudáveis, tanto em uma perspectiva individual, como na perspectiva da comunidade (SUNSTEIN, 2017, p. 1026).

A aplicação de insights da ciência comportamental já é realidade nas administrações públicas contemporâneas. Nos Estados Unidos, por exemplo, em 2015, o ex-presidente Obama, expediu um decreto para priorizar o uso da economia comportamental no âmbito da governança estatal.

No Brasil embora haja poucas experiências, destaca-se a NudgeRio, unidade criada na Prefeitura da Cidade do Rio, responsável por discutir e disseminar conceitos de economia comportamental. Este artigo faz, primeiramente, uma síntese da teoria comportamental e de seus conceitos fundamentais, para depois colocar em perspectiva as políticas públicas formuladas pelos cientistas da Prefeitura carioca, apresentando a evolução e o panorama atual dos seus projetos.

Desta forma, o estudo apresentará os conceitos basilares inerentes à teoria comportamental, explicando de que forma essas tendências cognitivas se conectam e como podem ser aplicadas na concepção das políticas regulatórias. Num segundo momento, mostraremos como essas ferramentas já estão sendo utilizadas pelos técnicos e cientistas da Prefeitura do Rio de Janeiro, para conceber e implementar ideias e projetos práticos e de baixo custo, concebidos a partir da ciência comportamental.

\section{Tendências cognitivas, heurísticas e vieses}

Tendências cognitivas são processos mentais inconscientes, que afetam as decisões e julgamentos que as pessoas fazem, geralmente conduzindo-as a escolhas pouco racionais. Estes pensamentos situam-se, portanto, no âmbito da racionalidade limitada, que destoa do modelo do homo economicus. Entre as tendências cognitivas, destacam-se as heurísticas e os vieses.

As heurísticas são atalhos mentais que nos ajudam a encontrar respostas adequadas, ainda que geralmente imperfeitas, para perguntas difíceis. Etimologicamente a palavra heurística vem da palavra grega Heuriskein, que significa "descobrir", e que também deu origem ao vocábulo Eureca (LAUKKONEN, SCHOOLER e TANGEN, 2018, p. 6).

Isoladamente as heurísticas não representam algo ruim e ocasionalmente podem facilitar a tomada de decisão. Todavia, quando esses atalhos fornecem uma resposta inadequada, violando sistematicamente nossa capacidade de tomar decisões racionais, teremos um viés cognitivo (KAHNEMAN, 2012, p. 127).

Os vieses cognitivos são capazes de distorcer ou limitar a nossa capacidade de tomar decisões racionais. Estes erros são fruto de uma resposta incompleta, que não permite que a decisão tomada seja ótima.

Muitas são as heurísticas e vieses descritas pela literatura de economia comportamental. Sem a pretensão de esgotar o tema, trataremos de seis tendências cognitivas que consideramos muito relevantes para o trabalho, seja por sua proeminência nos estudos da economia comportamental, seja por sua correlação com os Nudges potencialmente aplicáveis às políticas públicas. Trataremos delas nos tópicos a seguir:

\section{Ancoragem}

Também chamada de focalismo, esta heurística faz com que a exposição prévia a determinada informação nos leve superestimá-la na tomada de decisão, independentemente de sua relevância para o que está sendo decidido (BOUSSAIDI, 2013, p. 21). 
Nesse sentido, o efeito de ancoragem evidencia a dificuldade de alguém em se afastar da primeira impressão. Uma vez que uma âncora é estabelecida, há uma tendência de que os julgamentos sejam contaminados por ela.

Em 2007, GUTHRIE, RACHLINSKI e WISTRICH (2017, p. 30) descobriram que magistrados americanos eram suscetíveis aos efeitos da ancoragem ao proferir sentenças em casos de indenização. Na pesquisa, os juízes foram provocados a estipular uma condenação indenizatória por danos morais e materiais em um caso fictício de acidente de trabalho.

A amostra da pesquisa foi dividida em dois grupos de juízes: a) grupo controle, para o qual não foi apresentado nenhum valor inicial; b) grupo experimental, para o qual foi apresentada uma âncora. Este grupo experimental recebeu a informação de que "a empresa havia pedido a extinção do feito, alegando que a demanda não atingia o valor mínimo de U\$ 75.000 para ser processada naquela instância".

Os pesquisadores concluíram que os valores de indenização fixados eram menores no grupo experimental (média de 882 mil dólares), ou seja, que contava com uma informação-âncora, no caso, o valor de 75 mil dólares. Já no grupo controle, sem a âncora, a média das indenizações estabelecidas na sentença era de aproximadamente 1 milhão de dólares. Desta forma, os pesquisadores puderam comprovar a influência da ancoragem na tomada de decisão desses magistrados.

O resultado desta investigação não é isolado. GUTHRIE e KOROBKIN (1994, p. 11) descobriram que, em acordos judiciais, o valor apresentado como oferta inicial pode estabelecer uma âncora, impactando no restante das negociações e no valor final acordado.

\section{Disponibilidade}

A heurística da disponibilidade é a tendência de que as pessoas superestimem as chances de um evento acontecer, com base na frequência com que um exemplo vem à mente. De forma geral, as pessoas tendem a estipular a probabilidade de que determinado fato ocorra não de forma matemática e racional, mas com base em pensamentos recentes.

De acordo com THALER e SUNSTEIN (1974), eventos marcantes como ataques terroristas e desastres naturais fazem com que esses riscos sejam realçados em excesso, e, por conseguinte, sejam superdimensionados.

Da mesma forma, ARIELY et al (2008) destacam que vítimas de desastres ambientais estariam mais propensas à aquisição de seguros, se comparadas à indivíduos que não sofreram estas tragédias. Estes são efeitos da heurística da disponibilidade, que pode ser muito útil na implementação de políticas públicas.

Um exemplo clássico são as advertências feitas a fumantes nas embalagens de cigarro, chamando atenção para as eventuais consequências do consumo do tabaco. Estes alertas "disponibilizam" informações poderosas à memória do indivíduo, com a intenção clara de dissuadi-lo de um hábito prejudiciais.

Impende ressaltar que, na esfera governamental, abordagens desta natureza não alteram os incentivos econômicos existentes, ao passo que preservam a liberdade de escolha do cidadão. Para além disso, são enfoques simples, de baixo custo, e com grande potencial de equacionar problemas de políticas públicas.

\section{Excesso de otimismo}

As pessoas frequentemente superdimensionam as chances de eventos positivos em suas vidas, ao passo que tendem a subestimar a probabilidade de algo ruim acontecer com elas. Essa crença de que as coisas serão melhores no futuro é conhecida como viés do otimismo. Ser excessiva- 
mente otimista pode levar o indivíduo a tomar decisões ruins, na medida em que ele passa a negligenciar procedimentos que possam aumentar a sua segurança e a dos que estão ao seu redor (O'SULLIVAN, 2015, p. 11).

Para DEJOY (1989, p. 12), por exemplo, a mortalidade no trânsito pode ser associada à imprudência de motoristas excessivamente confiantes. Da mesma forma, SHARLOT $(2011$, p. 15) sugere que o excesso de otimismo pode levar um paciente a subestimar os sintomas iniciais de uma doença grave, atrasando o diagnóstico e levando-o a um tratamento tardio com menores chances de cura.

O estudo do viés do otimismo tem grande valia para a concepção e desenvolvimento de políticas públicas, pois não se pode ignorar a tendência do ser humano de tomar decisões pouco racionais contaminadas pelo excesso de confiança, o que engendra várias implicações sociais.

Podemos citar como exemplo: baixos índices - apontados por DOURADO et al (2015) - de uso de preservativos em relações sexuais para prevenção de DST's; a persistência do tabagismo em fumantes (embora conscientes dos malefícios do cigarro) detectada por MASIERO et al (2015); e as altas taxas de mortalidade de micro e pequenas empresas, diagnosticados pelo Sebrae (2016).

É interessante notar como o excesso de confiança pode ser reduzido por obra da heurística da disponibilidade. Tome-se o exemplo de uma campanha publicitária governamental, direcionada a motoristas, que exibe, em postos de gasolina, outdoors com o número de acidentes fatais que já ocorreram naquela via pública.

Neste caso, a heurística da disponibilidade trabalha para mitigar a influência do excesso de confiança nos motoristas, com vistas a atingir o resultado desejado (eles ficariam hesitantes em relação às suas habilidades, adotando uma postura mais prudente em relação ao tráfego, e, consequentemente, reduzindo acidentes).

Isso mostra que as tendências cognitivas podem interagir e associar-se entre si, e que o cientista comportamental pode extrair um grande aprendizado ao investigar essas possíveis comunicações entre heurísticas e vieses.

\section{Aversão à perda}

A aversão à perda faz o indivíduo atribuir maior importância às perdas do que aos ganhos, induzindo-o frequentemente a correr mais riscos no intuito de tentar reparar eventuais prejuízos. Este viés é decorrente da Teoria do Prospecto, na qual KAHNEMAN e TVERSKY (1979) sustentam que os indivíduos sentem muito mais a dor do prejuízo do que o prazer obtido por um ganho correspondente. Essa assimetria na forma como as perdas e ganhos são sentidos tem potencial para levar o indivíduo a tomar decisões pouco racionais, influenciadas pelo temor da perda.

Um exemplo é o investidor que, vendo sua aplicação desvalorizar, insiste no mesmo investimento sem perspectiva de melhora, seja pelo medo da dor de realizar prejuízo, seja pela recusa em admitir eventuais erros na escolha da aplicação. Outro exemplo é o consumidor que efetua uma compra impulsivamente, para não perder a "oportunidade" de adquirir o produto ou serviço com uma oferta especial. Um terceiro efeito potencialmente prejudicial desse viés é fazer o investidor liquidar precipitadamente as posições lucrativas e ainda promissoras, por receio de perder o que já foi ganho.

\section{Status quo}

O viés do status quo é uma preferência pelo estado atual das coisas. Um determinado padrão é aceito como sendo o ponto de referência, e qualquer desvio deste ponto passa a ser considerado uma perda ou um risco indesejado (SAMUELSON \& ZECKHAUSER, 1991, p. 10). A aversão à perda é a principal razão por trás de um viés de status quo. Quando confrontados com uma escolha, os indivíduos optam pela opção menos arriscada. Mesmo quando a tomada de decisão não exige muito esforço ou não traz riscos, ela pode ser simplesmente negligenciada ou ser realizada com desinteresse. Nestes casos, há uma 
tendência de manutenção da escolha feita, geralmente em função da desídia ou inércia do agente.

Partindo dessa premissa, o viés do status quo pode ser aproveitado para facilitar as escolhas do indivíduo no âmbito das políticas sociais. Ao interagir com o Estado, o indivíduo pode fazer várias escolhas de domínio público. Se em alguns contextos este indivíduo deixa de decidir expressamente, então alguma escolha padrão (também chamada default) será tomada.

Em países como a Áustria, por exemplo, as leis estabeleceram a doação de órgãos após a morte como escolha default. Portanto, as pessoas não-doadoras (ou seus representantes) devem protocolar, perante o governo, um documento optando por sair (o termo utilizado é opt-out) da regra-padrão (JOHNSON et al, 2002, p. 11). Na Áustria, onde a regra-padrão é a doação e o não-doador deve recusá-la expressamente, quase todos (99\%) concordaram com a doação (JOHNSON \& GOLDSTEIN, 2004, p. 1716). Richard Thaler (2009, p. 20) correlaciona o sucesso dessa experiência à adequada aplicação do viés do status quo, defendendo a implantação de políticas similares de opt-out para doação de órgãos nos Estados Unidos.

Portanto, para as decisões de domínio público, o estado tem a oportunidade de promover resultados de mercado mais racionais e desejáveis, selecionando standards apropriados, ou seja: definindo qual alternativa entrará em vigor se um indivíduo não fizer sua escolha.

\section{Desconto intertemporal}

O desconto intertemporal (ou hiperbólico) é a tendência de os indivíduos preferirem recompensas menores a curto prazo em vez de recompensas maiores a longo prazo. Em consequência disso, a percepção do valor de uma mesma coisa decrescerá, equivocadamente, no decurso do tempo.

Tradicionalmente, o desconto tradicional (ou exponencial) foi tratado pela Economia como uma porcentagem fixa, proporcional ao tempo de espera. Nara Melo exemplifica a situação:

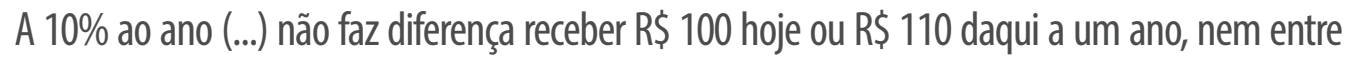
receber $R \$ 100$ daqui a um ano ou $R \$ 110$ daqui a dois anos, já que se trata da mesma taxa aplicada a um mesmo intervalo temporal (MELO, 2016, p. 1).

Todavia, os economistas comportamentais descobriram que, na prática, ao descontar no tempo o valor de algo a receber, o indivíduo tende a utilizar taxa variável de desconto (desconto hiperbólico). MELO (2016) esclarece que, pela lógica do desconto hiperbólico, "se tiverem que escolher entre receber $R \$ 100$ hoje ou $R \$ 110$ amanhã, muitas pessoas preferem a $1^{a}$ opção. No entanto, entre receber $R \$ 100$ daqui a um mês ou R\$ 110 daqui a um mês e um dia, costumam escolher a 2a". Ou seja, indivíduos tendem a fazer escolhas que eles mesmos não teriam feito, caso fossem capazes de se projetar no futuro e adiar a gratificação imediata.

Existem várias razões pelas quais as pessoas podem escolher racionalmente uma recompensa menor agora em vez de uma recompensa maior depois. Eles podem gostar da certeza, suas preferências podem mudar ao longo do tempo, ou podem ter uma necessidade urgente, como fome ou pagar o aluguel.

A principal aplicação do desconto intertemporal é na compreensão do comportamento de poupança dos indivíduos, explicando, por exemplo, o problema da subpoupança. Nesse sentido, este viés pode ser explorado para desenvolver formas de ajudar o indivíduo a poupar mais.

Foi com base em estudos sobre o desconto intertemporal, que BENARTZI \& THALER (2004, p. 164) conceberam e testaram o plano Save More Tomorrow (S.M.a.r.T.) em empresas norte-americanas. Com o auxílio de outros insights da ciência comportamental, como os vieses de status quo e aversão à perda, os cientistas desenvolveram mecanismos capazes de estimular os funcionários a pouparem recursos para o futuro (MORATO, 2020, p. 8). 


\section{Nudges aplicados às políticas públicas}

Os questionamentos acerca das heurísticas e vieses cognitivos levaram SUNSTEIN e THALER (2003) a defender a ideia de que é possível e legítimo afetar o comportamento individual por meio de abordagens baseadas na economia comportamental, desde que essas práticas não sejam coercitivas e respeitem a autonomia e liberdade de escolha do cidadão.

Segundo os autores, o paternalismo libertário é uma "abordagem que preserva a liberdade de escolha, mas que autoriza tanto as instituições públicas como as privadas a orientar as pessoas em direções que promoverão seu bem-estar". Dessa forma, seria possível minimizar ou reverter as falhas cognitivas do indivíduo, levando-o a realizar escolhas mais racionais e eficientes.

Desde o surgimento do paternalismo libertário, as técnicas de influência estudadas e sugeridas pelos especialistas comportamentais foram chamadas por diferentes nomes na literatura científica: "abordagens", "incentivos", "sugestões", "toques", etc.

Anos mais tarde, ao descrever esses modelos de abordagem comportamental, SUNSTEIN e THALER (2008) utilizaram o termo Nudge, algo como um "pequeno empurrão", que tem por escopo influenciar positivamente as decisões do indivíduo, a partir da compreensão dos seus limites cognitivos. Em inglês, Nudge representa uma espécie de "cutucada" sutil, geralmente com o cotovelo, a fim de chamar a atenção do sujeito para alguma coisa.

Desta forma, Nudge é apenas uma das formas de nomear esses pequenos incentivos que buscam reverter ou atenuar os efeitos dos vieses cognitivos, direcionando as escolhas dos indivíduos em um sentido mais racional. Os Nudges podem ser aplicados tanto na esfera privada (ex.: utilização de tendências cognitivas para incentivar práticas de poupança entre funcionários de uma empresa, como ocorreu no Save More Tomorrow) quanto no âmbito das políticas públicas (ex.: emprego do viés do otimismo e da disponibilidade para reduzir acidentes de trânsito).

Um Nudge pode usar, por exemplo, a heurística da disponibilidade para acentuar a percepção de risco para os tabagistas, através de advertências sobre questões de saúde nos maços de cigarros. A influência do design dos maços de cigarros nos hábitos dos fumantes está bem documentada em pesquisas, fazendo com que muitos usuários parem de fumar ou se esforcem para reduzir o número de cigarros fumados por dia (BANSAL-TRAVERS, 2011, p. 674).

Outra amostra da utilização de Nudges é o emprego do viés do status quo para a definição de opções default mais desejáveis ao bem-estar da coletividade. Verificando que os indivíduos apresentam resistência ou inércia para o deslocamento de opções default, Sunstein \& Thaler (2008) sugerem a formulação de políticas públicas que situem escolhas mais racionais como opções-padrão.

Como o ser humano nem sempre apresenta comportamentos absolutamente racionais e eficazes, os autores argumentam que, sobretudo em âmbito estatal, há fortes razões para a utilização de Nudges, pois eles são alternativas baratas, simples e com grande potencial para melhorar a eficácia e a qualidade das políticas públicas.

\section{Social and Behavioral Sciences Team (SBST)}

Entre 2014 e 2015, um pequeno grupo de cientistas comportamentais do Governo Federal dos EUA procurou, de forma experimental, formular propostas de Nudges para resolver problemas enfrentados por outras agências governamentais norte-americanas.

Uma das ideias do SBST foi o planejamento e envio de nove versões de um e-mail incentivando os funcionários públicos a se inscreverem em um programa de aposentadoria. Cerca de 720.000 e-mails foram enviados, com diferentes insights extraídos da economia comportamental.

Em relação ao grupo-controle (que não recebeu nenhum Nudge), o e-mail mais eficaz quase duplicou as taxas de inscrição, gerando 4.930 novos registros e US\$ 1,3 milhão poupados 
pelos contribuintes já no primeiro mês. A mensagem mais efetiva combinava instruções passo-a-passo de como se cadastrar, com um exemplo de quanto uma pessoa poderia poupar, economizando um pouco de dinheiro a cada mês.

Após este e outros experimentos ao longo de 2015, a Social and Behavioral Sciences Team entregou um relatório contendo todos estes dados ao então presidente Barack Obama sobre suas colaborações bem-sucedidas com diversas agências federais norte-americanas.

O documento apresentava resultados substanciais, demonstrando a eficácia do uso de Nudges em inúmeras políticas públicas: o já mencionado aumento da adesão em planos previdenciários por servidores públicos, melhoria das taxas de matrícula em universidades, redução da inadimplência em empréstimos estudantis e promoção da acessibilidade dos veteranos militares aos seus benefícios sociais.

Diante dos resultados positivos, em 15 de setembro de 2015, o presidente Barack Obama assinou a Executive Order 13.707, que institucionalizou a Social And Behavioral Sciences Team, emitindo uma diretriz para que as agências federais aplicassem a ciência comportamental no âmbito das políticas públicas.

\section{Behavioural Insights Team}

A Behavioural Insights Team (BIT), também conhecida como Nudge Unit, foi concebida pelo governo britânico para aplicar a metodologia comportamental no desenvolvimento e implementação de políticas públicas. Criada em 2010, trata-se da primeira instituição governamental do mundo dedicada a estudar intervenções que possam, através de $\mathrm{Nu}$ dges, encorajar, apoiar e capacitar as pessoas a fazer melhores escolhas para si e para a sociedade.

A BIT consolidou uma cultura de testes randomizados e experimentos controlados para a concepção e aperfeiçoamento de Nudges, desenvolvendo pesquisas e relatórios que entregam, com rigor científico, conclusões sobre a eficácia e o alcance de políticas públicas envolvendo estes incentivos.

De acordo com um boletim de 2015, a agência foi responsável por estimular mais de 100.000 pessoas a se registrarem como doadores de órgãos. Para tanto, a unidade aplicou conceitos da ciência comportamental, como o uso de mensagens com forte apelo emocional, incentivando a opção pela doação. Além disso, os cientistas introduziram chamadas para a doação de órgãos em sites de agências federais, como o DVLA (Driver and Vehicle Licensing Agency). Assim, motoristas que estavam, por exemplo, renovando suas carteiras online no site da DVLA, eram encorajados a acessar o site do Serviço Nacional de Saúde e mudar seu status para "doadores".

O BIT também fez com que devedores do Her Majesty's Courts and Tribunals Service (agência administrativa da justiça britânica) recebessem uma mensagem de texto dez dias antes de oficiais de justiça serem enviados in loco para entregar a notificação judicial. Isso duplicou os pagamentos feitos sem a necessidade de mais intervenções. Esta inovação teria economizado mais de 30 milhões de libras por ano aos cofres britânicos.

Originalmente criada como uma equipe dentro do gabinete ministerial, a BIT foi transformada em empresa limitada, sendo parcialmente vendida a alguns de seus funcionários e à NESTA (uma instituição britânica de caridade independente) em fevereiro de 2014. As agências federais que anteriormente haviam recebido sugestões sobre políticas agora pagam pelo serviço, uma vez que o custo de manutenção da equipe não é mais suportado pelo governo. 


\section{NudgeRio: uma experiência pioneira no Brasil}

\section{Programa Líderes Cariocas}

A Prefeitura do Rio de Janeiro vem executando, desde 2012, o Programa Líderes Cariocas (PLC). Esta iniciativa tem por escopo selecionar servidores públicos com perfil de liderança positiva e capacitá-los para assumir posições proeminentes na administração, elevando a produtividade e o desempenho dos trabalhos do executivo municipal.

Dentro dessa perspectiva inovadora, o PLC foi responsável pela idealização dos primeiros Nudges no setor público brasileiro, inspirando a criação, anos mais tarde, da NudgeRio, uma célula subordinada à Prefeitura do Rio de Janeiro, com o fim específico de aumentar a efetividade de iniciativas e políticas públicas através da aplicação da ciência comportamental.

O Programa é coordenado pelo Instituto Fundação João Goulart (IFJG) - órgão subordinado à Prefeitura do Rio - que tem enfoque na inovação das plataformas administrativas locais e na qualificação do funcionalismo público municipal, sobremaneira através da concepção, planejamento e implantação do Programa Líderes Cariocas.

\section{NudgeRio}

Em 2018 o Instituto Fundação João Goulart criou a NudgeRio, que visa dar continuidade aos primeiros projetos de ciência comportamental implementados pelo Programa Líderes Cariocas nos órgãos subordinados à Prefeitura do Rio de Janeiro.

A unidade tem como metas disseminar o conceito de Ciência Comportamental Aplicada nos órgãos da Prefeitura da Cidade do Rio de Janeiro - PCRJ, consolidar a execução de projetos Nudge e tornar-se referência para instituições governamentais municipais e estaduais.

Estes projetos baseiam-se em Nudges e são inspirados em unidades internacionais como a Behavioural Insights Team e a Social and Behavioral Science Team, visando aplicar estas experiências no desenho de políticas públicas mais eficazes. Nos tópicos seguintes, examinaremos projetos e resultados da NudgeRio.

\section{Aumento da matrícula online}

Atualmente, o município do Rio de Janeiro possui a maior rede de ensino pública da América Latina, contando com quase 650 mil alunos matriculados. A inscrição anual desses alunos é feita online, em dois momentos: pré-matrícula e matrícula definitiva. Como muitas famílias deixam de fazer a pré-matrícula online, a fase de matrícula definitiva, sobretudo nos dias finais do prazo, gera sobrecarga nas Coordenadorias Regionais de Educação, que prestam suporte físico aos pais e responsáveis pelo procedimento. Esse congestionamento gera filas, transtornos e exposição negativa na mídia para a Prefeitura do Rio de Janeiro.

Para resolver o problema, pesquisadores da Prefeitura conduziram, a partir de 2016, experimentos randômicos com base na metodologia comportamental e em heurísticas como a reciprocidade, escassez e norma social. Perguntas iniciais foram feitas pelos estudiosos, como por exemplo: "Quem são os responsáveis que irão realizar as novas matrículas?" e "Como acessar esses responsáveis?". A intervenção consistiu em estudar e reformular o processo de matrículas, atingindo, com maior eficácia, o público. Os dados sobre a metodologia e os resultados deste projeto foram extraídos de um paper divulgado pela FJG ("Aumento da Matrícula On-line", Fundação João Goulart, 2016, págs. 4-16).

Nesta fase de reformulação, os especialistas da Prefeitura projetaram textos baseados em heurísticas e vieses da Economia Comportamental com o objetivo de influenciar o comportamento dos receptores destas mensagens. Podemos identificar essas tendências cognitivas nos seguintes trechos: 
a) Reciprocidade (tendência do ser humano a sentir-se culpado por receber algo e não dar nada em troca):

Você sabia que cada vez mais pessoas fazem matrícula de seus(suas) filhos(as) nas Escolas da Prefeitura da Cidade do Rio de Janeiro pelo site? Em 2015 foram mais de 130 mil pessoas. Este ano, estimamos que muitos mais farão a inscrição pelo www.matricula.rio, com mais facilidade e economizando tempo. Não fique fora dessa e utilize o site para matricular seu(sua) filho(a)! ("Aumento da Matrícula On-line", Fundação João Goulart, 2016, p. 6).

b) Escassez (o indivíduo passa a ter mais interesse quando há risco de esgotamento da oferta):

Pelo site, você tem as mesmas opções de escolas e não precisa enfrentar fila nas Coordenadorias de Educação! Lembre-se que enquanto você está na fila para inscrever seu(sua) filho(a), outras pessoas já realizaram a inscrição em menos tempo e com muito mais conforto pela internet. ("Aumento da Matrícula On-line", Fundação João Goulart, 2016, p. 6).

c) Norma Social (as pessoas tendem a'aderir' o que a maioria está fazendo):

Você sabia que cada vez mais pessoas fazem matrícula de seus(suas) filhos(as) nas Escolas da Prefeitura da Cidade do Rio de Janeiro pelo site? Em 2015 foram mais de 130 mil pessoas. Este ano, estimamos que muitos mais farão a inscrição pelo www.matricula.rio, com mais facilidade e economizando tempo. "Não fique fora dessa e utilize o site para matricular seu(sua) filho(a)!" ("Aumento da Matrícula On-line", Fundação João Goulart, 2016, p. 6).

Além de redesenhar o website das matrículas, tornando-o mais intuitivo, os especialistas mapearam quais mensagens de e-mail poderiam ser mais efetivas para conseguir a adesão dos pais e alunos. De acordo com a NudgeRio, as reformulações propostas foram capazes de aumentar em até $55 \%$ o número de matrículas online em relação ao grupo controle.

A utilização destas e outras mensagens baseadas em ciência comportamental acabou com as enormes filas presenciais nos últimos dias de inscrição, contribuindo para reduzir o desconforto na hora da matrícula, bem como os custos com obras e recursos humanos para atender a esta demanda.

\section{Adesão ao tratamento da tuberculose}

Uma meta prioritária da Secretaria Municipal de Saúde do Rio de Janeiro é a redução dos altos índices de abandono do tratamento de tuberculose. Esta demanda foi encaminhada à NudgeRio em 2017 para ser examinada à luz da ciência comportamental.

O tratamento da tuberculose é rigoroso, com duração de 6 meses a 1 ano, e é feito através de antibióticos que devem ser tomados de forma regular e ininterrupta. O combate à doença também exige que o paciente adote um estilo de vida saudável, possibilitando a reação do sistema imunológico à doença (OLIVEIRA, MOREIRA FILHO, 1994, p. 437).

Por outro lado, o abandono do tratamento pode proporcionar o recrudescimento da doença, de forma ainda mais perigosa, uma vez que o agente infeccioso poderá voltar mais resistente aos fármacos disponíveis. 
Neste sentido, a NudgeRio procurou, em princípio, estabelecer as causas da não-adesão e do abandono do tratamento. Identificou que diversos fatores podem estar associados à não adesão e abandono do tratamento, entre eles os duros efeitos colaterais, o tempo de duração do tratamento, o baixo nível socioeconômico dos pacientes, internações por outras doenças, hábitos de vida e falhas no agendamento de consultas (Boletim Instituto Fundação João Goulart no 4, 2016, p. 5).

Desta forma, foram elaboradas estratégias para viabilizar um incremento tanto na aderência quanto na continuidade do tratamento da tuberculose, com base em estratégias de economia comportamental (Guia de Projetos de Líderes Cariocas e Gestores da Prefeitura da Cidade do Rio de Janeiro, Fundação João Goulart, 2015, p. 115).

A primeira delas é uma abordagem via telefone, cujo objetivo é coletar feedbacks sobre o quadro do paciente, além de lembrá-lo de retornar ao hospital para realizar a baciloscopia de controle, exame importante para a aferição do quadro. A outra é a distribuição de uma caderneta motivadora, que visa incentivar a utilização correta e regular dos antibióticos distribuídos (LIMA, 2017, p. 1).

\section{Redução de inadimplência no IPTU}

Os economistas comportamentais da Prefeitura do Rio de Janeiro substituíram o texto das cartas-padrão de inadimplência de IPTU (Imposto Predial e Territorial Urbano) por mensagens baseadas na ciência comportamental. Nas novas versões de cartas testadas, o objetivo era o mesmo: convencer o cidadão a quitar a dívida através de uma comunicação mais eficaz.

Essas novas mensagens tinham um feixe amplo de abordagens: desde um tom ameaçador (advertindo o contribuinte das implicações legais de ser inscrito na dívida ativa do município, por exemplo) até mensagens de "reforço positivo" contendo frases como "o bom cidadão paga os impostos"Erro! Indicador não definido..

O primeiro grupo de advertências utilizava a heurística do enquadramento, enfatizando uma das consequências do não pagamento do imposto (inscrição em dívida ativa), que normalmente, não é associada automaticamente pelo contribuinte ao atraso no IPTU. Já o segundo conjunto de mensagens explorou a heurística da norma social (SUNSTEIN, 2017, p. 1032), estimulando o cumprimento de regras habituais da comunidade, fornecendo ao agente um ponto de referência social: "o bom cidadão paga os impostos".

De acordo com um boletim de 2018 emitido pela Fundação João Goulart, a utilização dessas novas versões de cartas proporcionou um aumento efetivo de R\$ 120 milhões na arrecadação desde 2014 (Boletim da Fundação João Goulart n 03, 2018, p. 2).

A Fundação João Goulart também divulgou um paper demonstrando que, apenas em 2015, um projeto Nudge usando cartas de alerta identificou a mensagem mais efetiva que aumentou em $60 \%$ o número de devedores que pagaram ou renegociaram sua dívida de IPTU evitando entrarem na Dívida Ativa do Município (paper "Experimentos Controlados", disponível na seção "Projetos" do website da Fundação João Goulart).

\section{Dificuldades e desafios}

Algumas intervenções da NudgeRio não alcançaram os resultados esperados, como é o caso de um projeto de 2016, que visava reduzir o absenteísmo no $1^{\circ}$ Ano do Ensino Fundamental através do aperfeiçoamento da comunicação com os pais dos alunos da rede pública. Como os especialistas não obtiveram estatísticas satisfatórias, a unidade atualmente trabalha na reformulação do projeto, tendo como principal estratégia o envio de SMS aos pais, de modo a proporcionar o acompanhamento adequado da frequência escolar dos filhos. 
Outro obstáculo enfrentado pelos técnicos do governo municipal são as restrições orçamentárias. Em 2015, um projeto Nudge foi iniciado com o objetivo de reduzir possíveis situações arriscadas envolvendo pedestres em vias próximas ao VLT (Veículo Leve sobre Trilhos). Segundo a Fundação, o projeto ainda não foi concluído devido à falta de orçamento para a proposta de intervenção não-punitiva, que consiste na colocação de faixas de pedestres luminosas nas imediações do VLT.

Um outro projeto Nudge iniciado em 2016 tinha o objetivo de amenizar o congestionamento de veículos nas regiões de tráfego mais intenso. De acordo com a FJG, este plano ainda não foi colocado em prática devido à falta de verba para as executar as propostas de intervenção, que já foram desenhadas pelos especialistas da Prefeitura. Estas ideias consistem em intervenções não-punitivas e de baixo custo, que pretendem introduzir os seguintes elementos: a) semáforos com cronômetro; b) pinturas nas ruas de faixas de sinalização e imagens "3D"; c) faixas de pista inteligentes, que podem ser programadas por agentes da prefeitura conforme as necessidades do tráfego e d) equipamentos digitais que avisarão ao motorista, em tempo real, que ele está bloqueando um cruzamento, tendo como resultado final a redução do bloqueio de veículos em cruzamentos de vias públicas, especialmente de ônibus e caminhões.

\section{Considerações finais}

Pelo exposto, conclui-se que a ciência comportamental caminha a passos largos nas últimas décadas, adquirindo grande relevância acadêmica no campo da Economia, do Direito e da Psicologia. Dentre as várias tendências cognitivas já identificadas por essas pesquisas, foram destacadas aquelas que guardam maior relação com as políticas públicas: ancoragem, excesso de otimismo, disponibilidade, aversão à perda, status quo e desconto intertemporal.

O presente trabalho mostrou que o estudo da teoria comportamental tem permitido a formulação dos Nudges, incentivos que são capazes de reverter falhas cognitivas do indivíduo sem comprometer sua liberdade de escolha. Estes insights são baratos e fáceis de implementar e podem inspirar a criação de novas políticas públicas capazes de orientar positivamente as escolhas do cidadão.

Foi feita uma breve síntese dos primeiros experimentos práticos com Nudges, como as soluções propostas pela Behavioural Insights Team e a Social and Behavioral Sciences Team, agências cujas ideias adquiriram respaldo internacional, incentivando outros governos e empresas a aperfeiçoar o bem-estar de seus cidadãos e funcionários através da teoria comportamental.

O reconhecimento da eficácia dos incentivos comportamentais na vasta literatura científica, bem como as férteis experiências internacionais, nos leva a crer que seria fundamental a implantação de unidades Nudge institucionalizadas, ou seja, formalmente vinculadas aos poderes executivos no Brasil, a nível federal, estadual e municipal.

Desta forma, especialistas poderiam acompanhar e dar suporte intersetorial no desenho e execução de programas públicos, utilizando parâmetros da economia comportamental para garantir maior eficácia e alcance das ações a serem implantadas.

No Brasil, embora estas experiências ainda sejam incipientes, deve-se dar ênfase ao trabalho da NudgeRio, que colocou a Prefeitura Municipal do Rio na vanguarda da utilização de Nudges no setor público brasileiro. O projeto apresenta resultados salientes, e atualmente tem servido como referência para a discussão e disseminação da economia comportamental no Brasil.

Num contexto de desaceleração econômica, as estratégias da NudgeRio se apresentam como soluções inovadoras e acessíveis ao gestor, entregando resultados à sociedade mesmo com as atuais limitações orçamentárias da máquina pública.

É preciso sublinhar que, assim como nas demais políticas públicas, no caso dos Nudges é extremamente importante basear-se em evidências. Desta forma, testes empíricos, incluindo experiências aleatórias controladas, são indispensáveis (SUNSTEIN, 2017, p. 1024). Assim, durante os 
testes randomizados consequências adversas podem acontecer, e os gestores políticos devem estar constantemente atentos para essas adversidades, a fim de corrigir ou modificar o Nudge implementado.

No campo das evidências, os dados fornecidos pela Prefeitura Municipal do Rio indicam um desempenho satisfatório de parte das iniciativas implementadas. Dentre os resultados mais expressivos, a NudgeRio conseguiu aumentar a arrecadação de impostos, aperfeiçoando a comunicação com o contribuinte após uma série de testes e projeções. Os números exibidos pela Prefeitura comprovam que os experimentos conduzidos por seus cientistas comportamentais geraram um impacto efetivo de quase 120 milhões em arrecadação tributária.

No mesmo sentido, os dados divulgados pela FJG mostram que as intervenções efetivadas pela NudgeRio foram bem-sucedidas em aumentar as matrículas online através do envio de e-mails meticulosamente testados e melhorados pelos pesquisadores. O aumento de $55 \%$ das inscrições escolares em relação ao grupo-controle demonstrou que a NudgeRio obteve êxito com validade estatística.

Também é preciso sublinhar que os Nudges nem sempre terão o desempenho esperado, como mostrou-se no caso do projeto da NudgeRio para aumentar a frequência escolar de alunos do $1^{\circ}$ ano do ensino fundamental. Ou seja, é preciso reconhecer que, assim como ocorre nas outras políticas regulatórias, alguns Nudges parecem promissores na teoria, mas podem falhar na prática. Isso reforça ainda mais a necessidade de se executarem testes constantes, que possam melhorar a concepção inicial do Nudge, ou mesmo descartá-la, caso os experimentos demonstrem sua ineficácia.

Por fim, cabe ressaltar que a implantação de Nudges nas políticas públicas deve ser transparente e aberta à toda a sociedade. Quando comparados aos decretos e leis, a principal vantagem dos Nudges é que eles evitam a punição e a coerção. Desta forma, como bem observou SUNSTEIN $(2017$, p. 1027) incentivos comportamentais jamais devem assumir a forma de manipulação ou trapaça. $O$ cidadão e a sociedade civil devem ter acesso às informações e ter autonomia para examinar e reavaliar a utilidade e a eficácia dos Nudges, assim como ocorre (ou deveria ocorrer) em todas as iniciativas governamentais.

\section{6- Referências bibliográficas}

ANDRADE, JCS \& DIAS, CC. "Alcances e Limites da Teoria dos Jogos para a Análise de Situações de Interdependência". Anais do EnANPAD (Encontro Nacional da Associação Nacional de Pós-Graduação e Pesquisa em Administração, 2002), São Paulo. [acesso em 04/03/2020]. Disponível: http://www.anpad.org.br/admin/pdf/enanpad2002-eso-1573.pdf

ARIELY, D et al."The Tree of Experience in the Forest of Information: Overweighing Experienced Relative to Observed Information". Games and Economic Behavior. 2006.

BANSAL-TRAVERS $M$ et al. "The impact of cigarette pack design, descriptors, and warning labels on risk perception in the U.S". Am J Prev Med. 2011 Jun;40(6):674-82. [acesso em 21/05/2019]. Disponível: https://www.ncbi.nlm.nih.gov/pmc/articles/PMC3108248/

BENARTZI S \& THALER RH. “Save More Tomorrow ${ }^{\mathrm{TM}}$ : Using Behavioral Economics to Increase Employee Saving". Journal of Political Economy Vol. 112, №. S1, Papers in Honor of Sherwin Rosen: A Supplement to Volume 112. Fev 2004, pp. S164-S187 [acesso em 21/05/2019]. Disponível em https://www.jstor.org/stable/10.1086/380085?seq=1\#page scan tab contents

BEHAVIOURAL INSIGHTS LTD. "The Behavioural Insights Team Update report 2013-2015" Governo dos Estados Unidos da América. [acesso em 22/05/2019] Disponível em https://www.bi.team/ wp-content/uploads/2015/08/BIT Update-Report-Final-2013-2015.pdf

BOUSSAIDI R. "Representativeness Heuristic, Investor Sentiment and Overreaction to Accounting Earnings: The Case of the Tunisian Stock Market". Procedia - Social and Behavioral Sciences. 81. 9-21. 
DEJOY DM. "The optimism bias and traffic accident risk perception". Accident Analysis \& Prevention. Volume 21, Issue 4, August 1989

DOURADO et al. Revisitando o uso do preservativo no Brasil. Rev brasileira epidemiologia set 2015. [acesso em 20/05/2019]. Disponível em http://www.scielo.br/pdf/rbepid/v18s1/pt 1415-790X-rbepid-18-s1-00063.pdf

EXECUTIVE OFFICE OF THE PRESIDENT NATIONAL SCIENCE AND TECHNOLOGY COUNCIL. "SOcial and Behavioral Sciences Team 2016 Annual Report" Governo dos Estados Unidos da América [acesso em 20/05/2019] Disponível em https://sbst.gov/download/2016\%20SBST\%20Annual\%20Report.pdf

GOVERNO DOS ESTADOS UNIDOS DA AMÉRICA. “Executive Order 1370715 set 2015" [acesso em 20/05/2019] disponível em https://sbst.gov/download/Executive\%200rder\%2013707\%20 Implementation\%20Guidance.pdf

GUTHRIE C \& KOROBKIN R. "Psychological Barriers to Litigation Settlement: An Experimental Approach." Vanderbilt University's Institutional Repository. 1994. [acesso em 20/05/2019] Disponível em https://ir.vanderbilt.edu/bitstream/handle/1803/5837/Psychological Barriers to Litigation.pdf? sequence $=1$ \&isAllowed $=y$

GUTHRIE C, RACHLINSKI JJ \& WISTRICH AJ. "Blinking on the Bench: How Judges Decide Cases." Cornell Law Faculty Publications. Paper 917. 2017.

HAMMOND JS., RAIFFA, H \& KEENEY RL. "The Hidden Traps in Decision Making - The Hidden Traps in Decision Making". Clinical laboratory management review: Clinical Laboratory Management Association; 1998

JACKSON, C. "Behavioral science theory and principles for practice in health education". Health education research, Vol. 12, 1997

JOHNSON EJ, BELLMAN S \& LOHSE GL. “Defaults, Framing and Privacy: Why Opting In-Opting Out." Marketing Letters. 2002. [acesso em 20/05/2019]. Disponível em https://www0.gsb.columbia.edu/mygsb/faculty/research/pubfiles/1173/defaults framing and privacy.pdf

JOHNSON J \& GOLDSTEIN DG. “Defaults and Donation Decisions". Rev Transplantation, 78, 2004; pp. 1713-1716 [acesso em 20/05/2019]. Disponível em http://www.dangoldstein.com/papers/ JohnsonGoldstein Defaults Transplantation2004.pdf

LAUKKONEN R., SCHOOLER J. \& TANGEN, J M. "The Eureka Heuristic: Relying on insight to appraise the quality of ideas". PsyArXiv, Fev 2018 [acesso em 20/05/2019] Disponível em https:// psyarxiv.com/ez3tn/

LIMA, Luís. “O que o Nobel de Economia ensina à prefeitura do Rio de Janeiro". Revista Época. 09 de outubro de 2017.

MASIERO M, LUCCHIARI C \& PRAVETTONI G. “Personal Fable: Optimistic Bias in Cigarette Smokers". Int J High Risk Behav Addict. Mar 2015 [acesso em 20/05/2019]. Disponível em https://www. ncbi.nlm.nih.gov/pmc/articles/PMC4393561/

MELO, N. "Desconto hiperbólico - Mais vale um pássaro na mão". Website Penso logo invisto. Mai 2016. [acesso em 20/05/2019]. Disponível: http://pensologoinvisto.cvm.gov.br/desconto-hiperbolico-mais-vale-um-passaro-na-mao/

MORATO, O. “Utilizando economia comportamental nas políticas públicas para aumentar a doação de órgãos" Revista Themis - ESMEC/TJCE. Fortaleza, 2020.

MOREIRA-FILHO DC, OLIVEIRA HB. "Abandono de tratamento e recidiva da tuberculose: aspectos de episódios prévios", Rev. Saúde Pública, 34(5):437-443, 2000, São Paulo [acessado em 06 nov. 2012]. Disponível em: http://www.scielo. br/pdf/rsp/v34n5/3211.pdf 
O'SULLIVAN, OP. "The Neural Basis of Always Looking on the Bright Side. Dialogues in Philosophy", Mental and Neuro Sciences, 2015

Prefeitura do Rio de Janeiro. Boletim informativo da Fundação João Goulart. N 22 2017. [acesso em 22/05/2019]. Disponível em http://prefeitura.rio/documents/2601191/55a81bce-c$\underline{131-4154-9 a 10-e 19409037 d 57}$

Prefeitura do Rio de Janeiro. Fundação João Goulart. Boletim $n^{\circ} 3$ de 2018. [acesso em 22/05/2019] Disponível em http://www.rio.rj.gov.br/dlstatic/10112/7809870/4222522/BoletimFJG03 2018.pdf

Prefeitura do Rio de Janeiro. Fundação João Goulart. NudgeRio. Paper 'Aumento da matrícua online'. 2017 [acesso em 22/05/2019] Disponível: http://www.rio.rj.gov.br/dlstatic/10112/9430379/423410 1/papermatriculaonline2016.pdf

Prefeitura do Rio de Janeiro. Fundação João Goulart. Paper Travessia + Legal. 2018. [acesso em 20/05/2019]. Disponível em http://www.rio.rj.gov.br/dlstatic/10112/9430379/4234102/PAPERTRAVESSIALEGAL.pdf

Prefeitura do Rio de Janeiro. Fundação João Goulart. Programa Líderes Cariocas - Acelerando a progressão de servidores com perfil e ambição positiva de liderança. 2018. 38 Prêmio Ser Humano ABRH-RJ - Edição 2018. [acesso em 20/05/2019]. Disponível em http://rhnews.com. br/imagens $/ 2018 / 1 \% 20-\% 20$ Case $\% 20$ Programa $\% 20$ LCC3\%ADderes $\% 20$ Cariocas $\% 20 \% 20$ Funda\%C3\%A7\%C3\%A30\%20Jo\%C3\%A30\%20Goulart.pdf

Prefeitura do Rio de Janeiro. Secretaria Municipal da Educação. Educação em Números. Atualizado em Abr 2019. [acesso em 20/05/2019]. Disponível em http://www.rio.rj.gov.br/web/sme/ educacao-em-numeros

Sebrae. Sobrevivência de empresas no Brasil. 2016. [acesso em 23/05/2019] Disponível: www. sebrae.com.br/Sebrae/Portal\%20Sebrae/Anexos/sobrevivencia-das-empresas-no-brasil-relatorio-2016.pdf

SAMUELSON W \& ZECKHAUSER R. "Status Quo Bias in Decision Making". Journal of Risk and Uncertainty, v. 1, p. 7-59, 1988.

SHARLOT T. “The optimism bias" Current Biology. Volume 21, Dez 2011, pp. 941-945

THALER RH \& SUNSTEIN CR. "Libertarian Paternalism" Rev The American Economic Review. Vol. 93, No. 2, Papers and Proceedings of the One Hundred Fifteenth Annual Meeting of the American Economic Association, Washington, DC, January 3-5. Mai 2003, pp. 175-179

THALER RH \& SUNSTEIN CR. Nudge: Um pequeno empurrão - Como decidir em questões de saúde, riqueza e felicidade. Ed. Lua de papel. 2018.

THALER RH. "Opting in vs. Opting Out”. The New York Times. Set 2009 [acesso em 20/05/2019] Disponível em https://faculty.chicagobooth.edu/richard.thaler/assets/files/NYT09-27-2009. pdf

TVERSKY A. \& KAHNEMAN D. "Judgment under Uncertainty: Heuristics and Biases" Rev Science, New Series, Vol. 185, Sep. 27, 1974; pp. 1124-1131. 